\title{
Thermographic examination of prick test reactions with local anesthetic
}

\author{
Evgeni Stanev $^{1}$ (D) $\cdot$ Maria Dencheva $^{1} \cdot$ Maya Lyapina $^{2} \cdot$ Payam Forghani $^{1}$
}

Received: 17 April 2019/Accepted: 6 September 2019/Published online: 21 September 2019

(C) The Author(s) 2019

\begin{abstract}
In allergology, skin diagnostic tests are divided into epicutaneous, cutaneous and intracutaneous. The prick test is one of the cutaneous tests used most often for the diagnosis of hypersensitivity to local anesthetics. In the case of hypersensitivity to the examined anesthetic and reaction to the histamine-containing solution (positive control), inflammation appears with an increase in the local temperature. This warming can be detected objectively with a thermal camera and can be used in the diagnostic process. This study was used to examine the capabilities of the infrared thermography application, in the prick test of both men and women, by comparing temperature changes and the intensity of allergic inflammation in the positive and negative controls in addition with a negative reaction to an allergen. A group of 115 patients-55 male (52\%) and 60 female (48\%), are included. All are examined for hypersensitivity to Mepivastesin, together with the positive and negative control. Skin temperature changes of the skin were examined with FLIR A320 thermal camera and the FLIR Reporter Professional software 2013-application used to process the thermal camera images and data. The statistical analysis shows a marked temperature difference between men and women. Similarities in temperature values are detected between the negative reactions to dental anesthetic and the negative control. However, the latter substantially differs from the data obtained with the positive control. Results of the research indicate the possible applications of the thermography diagnostics in evaluation of the prick test results.
\end{abstract}

Keywords Immediate hypersensitivity $\cdot$ Skin test $\cdot$ Infrared thermography $\cdot$ Skin temperature

\section{List of symbols}

$\Delta \mathrm{Ar} \quad$ The change in temperature of the skin after performing the test with the allergen

$\mathrm{Ar}_{2} \quad$ The post-reaction temperature of the skin after performing the test with the allergen

$\mathrm{Ar}_{1} \quad$ The pre-reaction temperature of the skin after performing the test with the allergen

$\Delta \mathrm{Neg}$ The change in the temperature of the skin after performing the test with the negative control

$\mathrm{Neg}_{2}$ The post-reaction temperature of the skin after performing the test with the negative control

$\mathrm{Neg}_{1}$ The pre-reaction temperature of the skin after performing the test with the negative control

Evgeni Stanev

stanev242@gmail.com

1 Faculty of Dental Medicine, Medical University, Sofia, Sofia, Bulgaria

2 Medical College "J. Filaretova", Medical University, Sofia, Sofia, Bulgaria
$\Delta \mathrm{Pos} \quad$ The change in temperature of the skin after performing the test with the positive control

$\mathrm{Pos}_{2}$ The post-reaction temperature of the skin after performing the test with the positive control

$\mathrm{Pos}_{1}$ The pre-reaction temperature of the skin after performing the test with the positive control

$\Delta \mathrm{Ar}^{\prime} \quad$ The change of the temperature due to the allergic reaction

\section{Introduction}

Prick test is a cutaneous test, used to evaluate the hypersensitivity of the organism to immunoglobulin E (IgE)mediated reactions. It is performed with allergens, a positive and a negative control, on the skin of the forearm. Reactions are assessed after $20 \mathrm{~min}$, and reactions with papules and erythema more than $3 \mathrm{~mm}$ in diameter are considered positive. Standardization of skin test procedures and standard panels for different geographic locations are 
encouraged worldwide to permit better comparisons for diagnostic, clinical and research purposes [1].

Infrared thermography examination is a noninvasive contactless diagnostic method for human body through which temperature fluctuations can be shown on a display and recorded accordingly. It can be used in oncology, angiology, rheumatology and other fields in medicine [2].

In the field of allergology, it is used in the diagnostics of different pathological conditions [3].

This diagnostic method can also be applied in the diagnosis of other types of allergic reactions when used in conjugation with skin testing. This is due to the fact that allergic inflammatory reaction, like all other types of inflammatory reactions, is manifested with five basic symptoms - tumor, rubor, calor, dolor and functio laesa. These reactions are due to the inflammatory mediators produced by the cells of the immune system. Mast cells and the histamine they release are the main factors in prick test $[4,5]$. Therefore, for the positive control, a solution of histamine is used to imitate a positive allergic reaction.

\section{Materials and methods}

The test group consists of 115 patients (other 28 patients were not included, because they are contraindicated for the prick test according to the European standards [1]) - 55 male $(52 \%)$ and 60 female (48\%), aged 24 ( \pm 2 years), in the hours between 8:00 am and 12:00 pm, at the Faculty of Dental Medicine in the Medical University of Sofia. The decision for the number of patients for the test group is made and approved by a licensed statistician. They are tested for hypersensitivity to Mepivastesin-30 $\mathrm{mg} \mathrm{mL}^{-1}$ : containing mepivacaine hydrochloride, natrium chloride and distilled water. For the positive control, $10 \mathrm{mg} \mathrm{mL}^{-1}$ histamine dihydrochloride as an active ingredient is used in a solution for the skin prick test. The negative control has no active ingredient, and it requires control, however, using diluent. The National Center for Infectious and Parasitic diseases in Bulgaria produces and manufactures the aforementioned solutions.

\section{Ethical approval and informed consent}

The study is approved by the Medical Ethics Board at Medical University-Sofia. All the participants are informed about the purpose of the study and give their written informed consent before its commencement.

The prick test is performed with calibrated plastic lancets (Stallerpointer ${ }^{\circledR}$ ) with a 1-mm sharped pointed edge at the terminal part of the lancet.

Temperature changes of the skin are examined with the FLIR A320 thermal camera and the respective software for processing the images and data-FLIR Reporter Professional software 2013.

To specify the target places on the skin (through the thermography application) where the test is performed, a brace for the forearm is formulated and constructed with 3D printing technology (Fig. 1).

This brace ensures repeatability, reliability and unambiguity of the results. The patient puts his forearm in the brace, and the 2nd, 3rd and 4th circular zones (Fig. 2) are chosen as the location for the test-one for the allergen, one for the negative control and the other for the positive control.

The brace has two supports for the forearm at the base, ensuring fixed position (Fig. 3) of the forearm with minimum contact, while warranting patient comfort. The minimum contact as opposed to contact with a wider surface minimizes errors in the variance of temperatures.

The brace has been constructed as to allow the following dimensions of a forearm: length $-35 \mathrm{~cm}$, wide $-15 \mathrm{~cm}$ and thickness $-12 \mathrm{~cm}$. Over the supports of the brace, a plastic rectangle exists, containing 5 holes with a fixed distance between them. The rectangle is adjustable, so it can cater to the specific anatomy of the patients forearm. There is a clear gradient between the temperature of the skin and the ambient temperature of the brace. Due to this, the reactions are differentiated by their clearly visible borders in the thermographic images. Thus, the places of the contact of the allergen with the skin can be clearly seen, and therefore, the temperature in these areas (Ar) (Fig. 4) is evaluated.

The brace is constructed of aluminum rods with diameter $6 \mathrm{~mm}$ in addition with plastic elements created on a $3 \mathrm{D}$ printer using the fused deposition modeling technique.

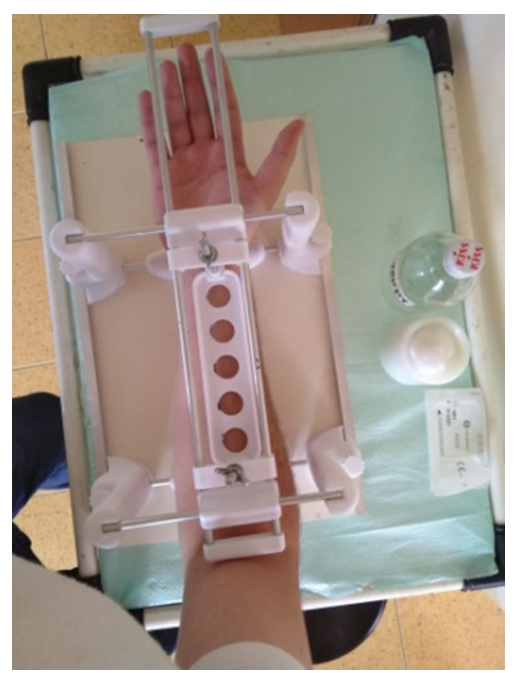

Fig. 1 Brace for stabilising and outlining the zones of contact between the allergen and the skin 


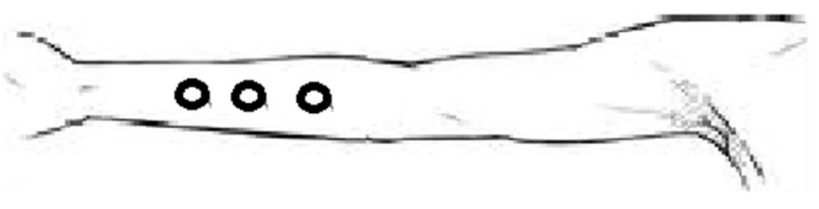

Fig. 2 Zones where the test is performed

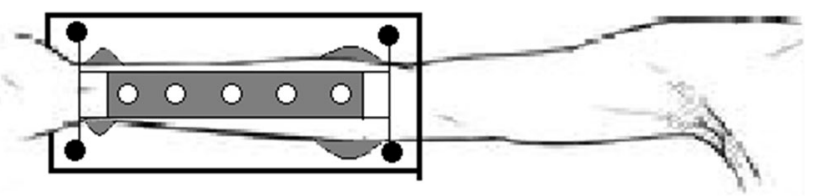

Fig. 3 Forearm placed in the brace in preparation for the thermovision evaluation

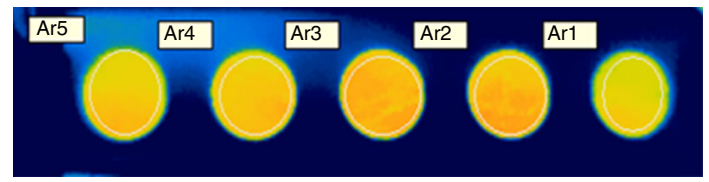

Fig. 4 Thermographic image of the forearm, mounted in the brace, covered by the plastic rectangle with the five openings

The prick test procedure is performed as set out by the rules stated in the European standards [1]. After anamnesis is taken, the patients forearm is placed in the brace. The initial thermographic image is recorded and examined, in order to detect superficial blood vessels below the skin surface which is to be tested. Trauma may occur of the superficial blood vessels of patients with little subdermal adipose during the pricking. It is of upmost importance that the latter trauma is carefully avoided in order to have valid results and data for the diagnostic test. On the thermography application, the blood vessels are seen as long thin zone of increased temperature compared with the surrounding tissue (Fig. 5). Zones which are contraindicated for the procedure are areas of the skin with tattoos and any other skin changes.

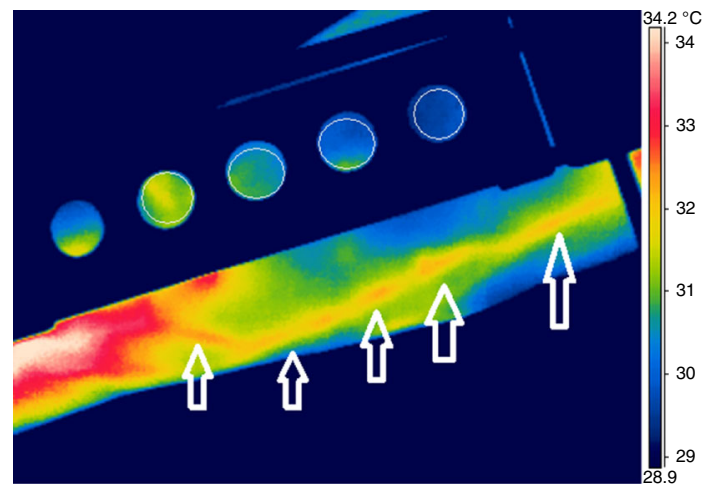

Fig. 5 Thermographic image of the forearm, arrows are showing the blood vessels with demarcated borders

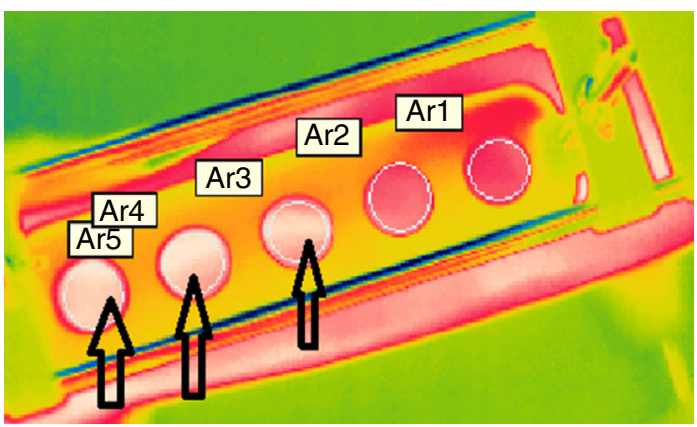

Fig. 6 Blood vessel passing through $\mathrm{Ar}_{3}, \mathrm{Ar}_{4}, \mathrm{Ar}_{5}$

Areas with superficial blood vessels should not be included in the examined areas. For this reason, the forearm can be repositioned (Fig. 6).

The initial thermography picture is also used for the analysis of the results. It provides information for the temperature prior to the test and the normal temperatures. Using the software, these areas are marked, and the results for the average temperatures in the three areas of examination are obtained.

After securing the forearm correctly in the brace, the three areas are marked with a skin marker and the patients forearm is released from the brace. The prick test is performed by placing a drop of the allergen onto the skin and after this area is pricked with the plastic lancet once. The procedure is repeated with the positive and the negative control. After $20 \mathrm{~min}$, the forearm is secured into the brace again, in the same position as it was during the first test, by using the marks on the skin to achieve this.

The second image is captured after the test, and it provides information regarding the temperature changes when the reactions had occurred (Fig. 7).

The papules and erythema are measured, to assess whether there is a positive reaction to the allergen. If the diameter of the latter is $3 \mathrm{~mm}$ or above, then it is considered as a positive reaction.

\section{Analysis of the average recorded temperatures}

The zones of the reaction are specifically marked using the software, and then, the software calculates the average temperature. For every marked zone, the change in

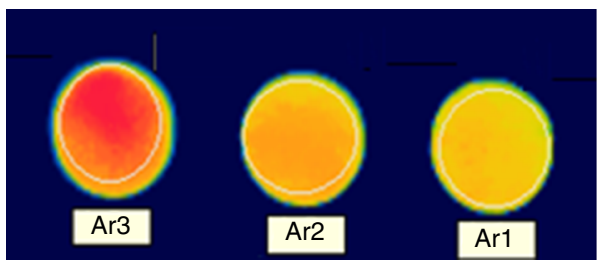

Fig. 7 Thermographic image after the prick test - allergen $\left(\operatorname{Ar}_{1}\right)$, negative control $\left(\mathrm{Ar}_{2}\right)$, positive control $\left(\mathrm{Ar}_{3}\right)$ 
temperature of the skin after performing the test is calculated by using the following formula:

$\Delta \mathrm{Ar}=\mathrm{Ar}_{2}-\mathrm{Ar}_{1}$

where $\mathrm{Ar}_{2}$ is the post-reaction temperature and $\mathrm{Ar}_{1}$ is the pre-reaction temperature.

The same calculation is performed for the negative and positive tests as follows

$\Delta \mathrm{Neg}=\mathrm{Neg}_{2}-\mathrm{Neg}_{1}$

where $\mathrm{Neg}_{2}$ is the post-reaction temperature and $\mathrm{Neg}_{1}$ is the pre-reaction temperature

$\Delta \mathrm{Pos}=\mathrm{Pos}_{2}-\mathrm{Pos}_{1}$

where $\operatorname{Pos}_{2}$ is the post-reaction temperature and $\operatorname{Pos}_{1}$ is the pre-reaction temperature.

There is no allergic reaction in the negative control. Patient induced factors; the environment and trauma from the pricking can affect the temperature. The negative control is used to compare the other two reactions and to assess them against each other. The change of the

Table 1 Descriptive statistics-information for the values before and after the prick test

\begin{tabular}{llll}
\hline & Min $\left({ }^{\circ} \mathrm{C}\right)$ & Max $\left({ }^{\circ} \mathrm{C}\right)$ & Mean \pm SD $\left({ }^{\circ} \mathrm{C}\right)$ \\
\hline $\mathrm{Ar}_{1}$ & 30.1 & 35.7 & $33.4 \pm 1.00$ \\
$\mathrm{Neg}_{1}$ & 30.1 & 36.1 & $33.6 \pm 0.96$ \\
$\mathrm{Pos}_{1}$ & 31.3 & 35.8 & $33.7 \pm 0.94$ \\
$\mathrm{Ar}_{2}$ & 30.1 & 34.8 & $32.5 \pm 1.11$ \\
$\mathrm{Neg}_{2}$ & 30.7 & 35.2 & $32.9 \pm 1.05$ \\
$\mathrm{Pos}_{2}$ & 31.6 & 35.9 & $33.9 \pm 1.04$ \\
\hline
\end{tabular}

Min is the minimum temperature value

Max is the maximum temperature value

Mean is the mean temperature value, and SD is the standard deviation

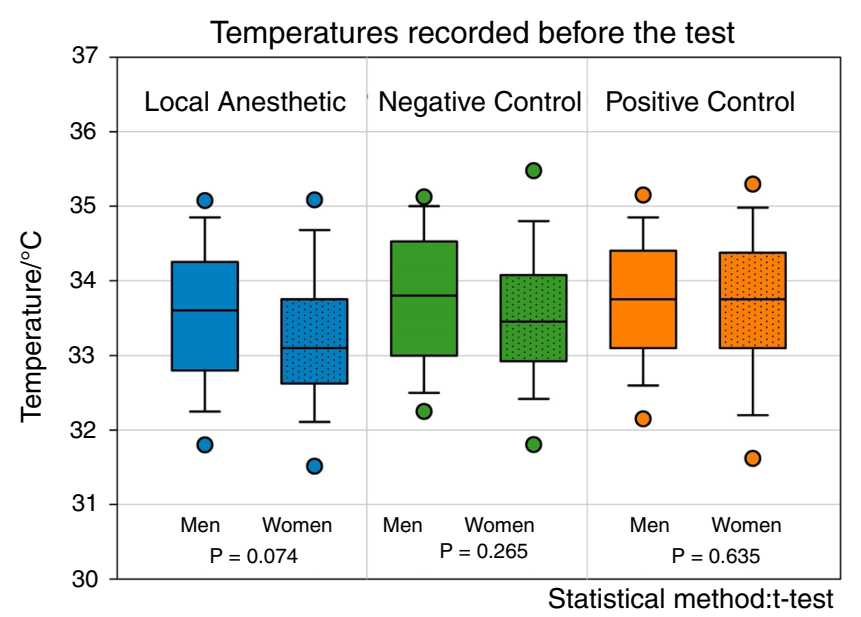

temperature due to the allergic reaction can be calculated using $\Delta \mathrm{Ar}^{\prime}$, where

$\Delta \mathrm{Ar}^{\prime}=\Delta \mathrm{Ar}-\Delta \mathrm{Neg}$

In the case of a positive reaction, it is expected that $\Delta \mathrm{Ar}^{\prime}$ is greater than zero. The greater the inflammation, a higher value of $\Delta \mathrm{Ar}^{\prime}$ is expected. In the cases with the absence of an allergic inflammation, $\Delta \mathrm{Ar}^{\prime}$ is expected to be less or around zero. Due to the many factors that affect the skin temperature during this 20 -min period, it is expected to have some deviations in the value.

\section{Statistical analysis}

The statistical analysis is performed using the SPSS 17.0 software. Paired two-tailed $t$ test is used to identify the differences between the temperatures in the fields before and after the prick test and for difference in the results of male and female temperatures. Significance level of a hypothesis test is set as $p=0.05$.

\section{Results}

The descriptive statistics (Table 1) provide information for the values before and after the prick test. The temperature range of the examined areas before the test is $30.1-36.1{ }^{\circ} \mathrm{C}$. After the test, the temperature range of the reactions is shown in Fig. 8:

- Allergen (negative) is $30.1-34.8^{\circ} \mathrm{C}$ (male 30.9-34.8 ${ }^{\circ} \mathrm{C}$; female $30.1-34.6{ }^{\circ} \mathrm{C}$ )

- Negative control is $30.7-35.2{ }^{\circ} \mathrm{C}$ (male $30.7-34.7{ }^{\circ} \mathrm{C}$; female $30.8-35.2{ }^{\circ} \mathrm{C}$ )

- Positive control is $31.6-35.9{ }^{\circ} \mathrm{C}$ (male $32.3-35.9{ }^{\circ} \mathrm{C}$; female $31.6-35.9^{\circ} \mathrm{C}$ )

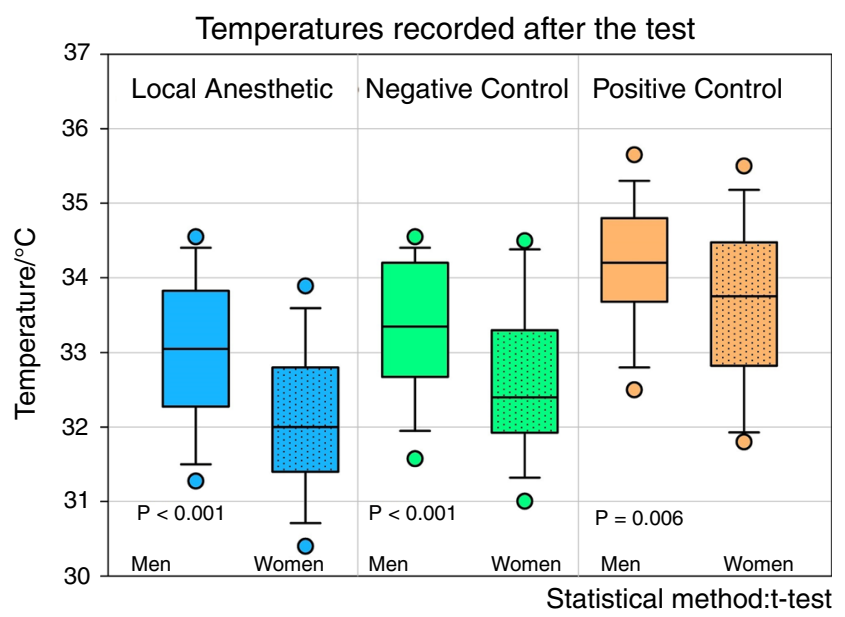

Fig. 8 Temperatures recorded before and after the test in men and women 
The results show a single positive reaction to Mepivastesin; however, the others were negative.

A statistically significant difference is detected: $\mathrm{Pos}_{2}$ values are greater than $\operatorname{Ar}_{2}(p<0.001$; male $p<0.001$; female $p<0.001)$, and the $\operatorname{Pos}_{2}$ values are greater than $\mathrm{Neg}_{2}(p<0.001$; male $p<0.0001$; female $p<0.001)$.

After statistical analysis (paired $t$ test), similarities are detected between the changes of the negative reactions to Mepivastesin $(\Delta \mathrm{Ar})$, and the reactions to the negative control $(\Delta \mathrm{Neg})(p<0.001)$. Similarly, it is detected that $\Delta \operatorname{Pos}>\Delta \operatorname{Ar}(p<0.001)$ and $\Delta \operatorname{Pos}>\Delta \operatorname{Neg}(p<0.001)$.

The values of $\Delta \mathrm{Ar}^{\prime}$ are less than $0.5{ }^{\circ} \mathrm{C}$ in $96 \%$ of the cases and is more than $0.5{ }^{\circ} \mathrm{C}$ in the positive reaction. There is no significant difference between men and women for the values of $\Delta \mathrm{Ar}^{\prime}$.

Similarly, there is no significant difference in the initial thermographic images between men and women in the initial thermographic images (prior to the test). The mean temperatures of the skin of the forearm for men are: $\mathrm{Ar}_{1}-$ $33.5^{\circ} \mathrm{C}, \mathrm{Neg}_{1}-33.7{ }^{\circ} \mathrm{C}, \mathrm{Pos}_{1}-33.7^{\circ} \mathrm{C}$, and for women are: $\mathrm{Ar}_{1}-33.2{ }^{\circ} \mathrm{C}, \mathrm{Neg}_{1}-33.5^{\circ} \mathrm{C}, \mathrm{Pos}_{1}-33.6^{\circ} \mathrm{C}$.

However, in the second thermographic images (after the test), there exists a significant difference between men and women in the three examined areas: the area with the allergen $(p<0.001)$, the area of the negative control $(p<0.001)$ and the area of the positive control $(p=0.006)$. The mean temperatures of the skin of the forearm for men are: $\mathrm{Ar}_{2}-33.0{ }^{\circ} \mathrm{C}, \mathrm{Neg}_{2}-33.3{ }^{\circ} \mathrm{C}$, $\mathrm{Pos}_{2}-34.1^{\circ} \mathrm{C}$, and for women are: $\mathrm{Ar}_{2}-32.0^{\circ} \mathrm{C}, \mathrm{Neg}_{2}-$ $32.6{ }^{\circ} \mathrm{C}, \mathrm{Pos}_{2}-33.6{ }^{\circ} \mathrm{C}$ (Fig.8).

\section{Discussion}

Changes in temperature can be because of different factors, all of which affect the reactions-mechanical trauma from the lancet (technical factor), circadian rhythms (individual factor), the ambient temperature of the room (environmental factor). Each of the aforementioned factors can produce an individual fluctuation in the temperature; however, together they form the combined difference in the temperature. The final result of this combination can be seen as the temperature difference of the negative control $(\Delta \mathrm{Neg})($ Table 2$)$

These factors are divided into three primary groups [6]:

\section{Environmental factors}

These factors are affected by the place of the examination: area of the room, the ambient temperature, relative humidity, atmospheric pressure, infrared radiation pollution.

\section{Individual factors}

These factors refer to the individual patient and his/her particular characteristics which could affect the skin temperature. These factors are divided into intrinsic and extrinsic factors. Intrinsic factors are as follows: sex, age, anthropometry, circadian rhythm, hair density, skin infrared emission, medical history, metabolic rate, skin blood flow, genetics, emotions. Extrinsic factors are as follows: pharmaceutical consumption and nutrition, remedies, physical activity.

\section{Technical factors}

Factors related to the apparatus used during the infrared thermography (IRT) evaluation are: validity, reliability, repeatability, procedure, camera, software, statistical analysis.

According to Bernstein et al. [7], histamine reactivity in the skin varies among individuals, independent of skin test reactivity to allergens. The skin test results to allergens should not be related to the size of the histamine reaction [8]. The size of the wheal is not solely due to histamine, as some subjects with a positive skin prick test reaction show no significant histamine release to these allergens, as assessed by microdialysis technique [9]. There is a high correlation between conventional methods of examination and results obtained from thermal imaging, which opens possibilities for the use of thermovision as a complementary addition to the conventional methods used in medicine. [10].

Before the completion of the test, there is not a statistically significant difference between the temperatures of the skin areas of men and women; however, after the test, there exists a statistically significant difference $(p<0.001)$. The temperature of the skin areas of the forearm after the prick test in the allergen area decreases in both genders, however, with different temperature values in each gender. In women, it is relatively higher

Table 2 Factors which affect the variable

$\Delta \mathrm{Ar} \quad$ Factors of the environment, factors of the individual, technical factors and errors, eventual allergological inflammation

$\Delta \mathrm{Neg}$ Factors of the environment, factors of the individual, technical factors

$\Delta$ Pos Factors of the environment, factors of the individual, technical factors, allergological inflammation as a direct result of the histamine

The bold text contain factors who are specific for the parameters in the group 
$\left(-1.15^{\circ} \mathrm{C}\right)$ as compared to the temperature change in men $\left(-0.52{ }^{\circ} \mathrm{C}\right)$. The reaction in the positive control among men is demonstrated with an increase in temperature of the examined skin area (mean $0.46{ }^{\circ} \mathrm{C}$ ); however, in women there is a negligible change $\left(-0.01{ }^{\circ} \mathrm{C}\right)$. In the negative control, in both genders there appears to be a decrease in temperature; however, it is a more significant reduction in temperature in women $\left(-0.92{ }^{\circ} \mathrm{C}\right.$ compared to $-0.42{ }^{\circ} \mathrm{C}$ in men). The gender of the patient is of importance when analyzing the processes of the organism linked to the changes in temperature (Fig. 9).

The potential of the infrared thermography in the diagnostic of inflammations is proven by Grozdanova et al. [11] and disturbance fields in the maxillofacial area. The thermographic assessment of the allergic skin test is also used for the patch test. The more intensive reactions indicate an increased temperature $[12,13]$. Szwedo and Tomaka calibrate the method and declare that the infrared thermography in the field of medicine should be further developed, as this will improve the evaluation of skin tests [14]. One of the five signs of inflammation is temperature.

Rokita et al. (2011) examined 24 patients with prick tested patients in combination with thermographic analysis; histamine was also used as a positive control. In this study, 7 variables were detected with varying reliability. The results show that the combination of the thermographic image together with the mathematical analysis is a new method to examine the intensity of the reactions [15]. According to the newest research of Rok et al. [16], the infrared thermography is a method which allows highlighting the hypersensitivity patients and automatic correction of the diagnosis.

In our study, a single positive reaction to Mepivastesin was registered. This anesthetic does not contain vasoconstrictor (adrenalin); this is why it is suitable for investigation of allergic reactions. This confirms the results of Dencheva et al. (2018) concerning the frequency of positive allergic reactions to dental local anesthetics. The $\Delta \mathrm{Ar}^{\prime}$ can be used for quantitative measurement of the intensity

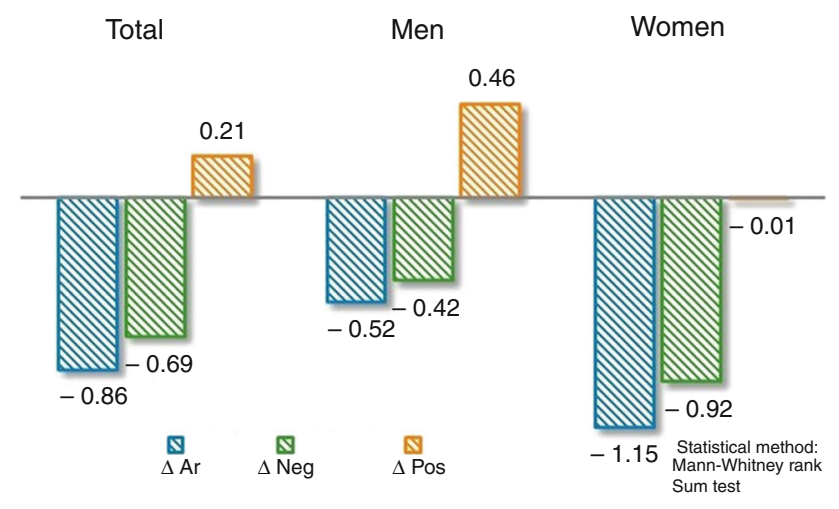

Fig. 9 Temperature changes in men and women of the reaction. The value of 0.5 for $\Delta \mathrm{Ar}^{\prime}$ can be used as a limit. If it is less than 0.5 , the reaction can be accepted as a negative, and if it is greater, it can be accepted as a positive result. The reliability of the results will be $97 \%$. The lack of variation in results between men and women concerning $\Delta \mathrm{Ar}^{\prime}$ proves that it can be used for both genders [17].

\section{Conclusion}

Using the infrared thermographic imaging methodology, the infrared emission of the skin is measured accurately, which is independent from the other two signs of the inflammation-erythema and papule. Therefore, combining the thermographic diagnostics with the traditional methods of assessing prick tests, a better prospective of the results is successfully achieved. Describing the values of $\mathrm{Ar}_{2}, \Delta \mathrm{Neg}, \Delta \mathrm{Pos}, \Delta \mathrm{Ar}$ and $\Delta \mathrm{Ar}^{\prime}$ provide us a better understanding of the temperature variations of the reactions and for the complex process of inflammation. A software which can automatically calculate $\Delta \mathrm{Ar}$ and $\mathrm{Ar}^{\prime}$ should be designed and become a tool in dental offices where allergic tests are common practice. This software can aid the practitioner to assess the allergic reactions. Further studies should be performed in this area.

Acknowledgements This work was an individually funded research.

Author contributions All the authors have collaborated in conception and design of the study, in drafting the article, bibliographic search and have approved its final version.

Funding No funding has been received for this manuscript.

\section{Compliance with ethical standards}

Conflict of interest The authors declare that they have no conflicts of interest.

Open Access This article is distributed under the terms of the Creative Commons Attribution 4.0 International License (http://creative commons.org/licenses/by/4.0/), which permits unrestricted use, distribution, and reproduction in any medium, provided you give appropriate credit to the original author(s) and the source, provide a link to the Creative Commons license, and indicate if changes were made.

\section{References}

1. Heinzerling L, Mari A, Bergmann KC, et al. The skin prick testEuropean standards. Clin Transl Allergy. 2013;3(1):3.

2. Lahiri BB, Bagavathiappan S, Jayakumar $\mathrm{T}$, et al. Medical applications of infrared thermography: a review. Infrared Phys Technol. 2012;55(4):221-35.

3. Fileva I, Petkova E, Stanev E, et al. Thermovision in diagnostics of allergic diseases. Allergy. 2018;73:140. 
4. Galli SJ, Tsai M. IgE and mast cells in allergic disease. Nat Med. 2012;18(5):693.

5. Dencheva M, Balcheva M. Dental clinical allergology. Sofia (BG); 2014.

6. Fernández-Cuevas I, Marins JCB, Lastras JA, et al. Classification of factors influencing the use of infrared thermography in humans: a review. Infrared Phys Technol. 2015;71:28-55.

7. Bernstein IL, Storms WW. Practice parameters for allergy diagnostic testing. Joint Task Force on Practice Parameters for the Diagnosis and Treatment of Asthma. The American Academy of Allergy, Asthma and Immunology and the American College of Allergy, Asthma and Immunology. Ann Allergy Asthma Immunol Off Publ Amer Coll Allergy Asthma Immunol. 1995;75(6 Pt 2):543.

8. Derer T. Critical evaluation of the use of skin tests and cellular tests in standardization of allergens. Arbeiten aus dem PaulEhrlich-Institut (Bundesamt fur Sera und Impfstoffe) zu Frankfurt aM. 1994;87:89-114.

9. Horsmanheimo L, Harvima IT, Harvima RJ, et al. Histamine release in skin monitored with the microdialysis technique does not correlate with the weal size induced by cow allergen. $\mathrm{Br} \mathrm{J}$ Dermatol. 1996;134(1):94-100.

10. Cholewka A, Kasprzyk T, Stanek A, Sieroń-Stołtny K, Drzazga Z. May thermal imaging be useful in cyclist endurance test. J Therm Anal Calorim. 2016;123:1973-9.
11. Grozdanova R, Uzunov T, Kisselova A, et al. Electronic protocol for oral focal diagnostics. Probl Dent Med. 2012;38:42.

12. Dencheva M, Lyapina M, Kisselova-Yaneva A, et al. Thermovision in dental allergology. J IMAB Annu Proc Sci Pap. 2014;20(3):558-62.

13. Stanev E, Dencheva M. Thermographic proof of "Flare up syndrome" in patient with allergy to acrylic materials. MedInform. 2018;2:811-22.

14. Szwedo M, Tomaka B. Evaluation of patch tests results-research and development of technique based on infrared thermography. Diagnostyka. 2015;16:4.

15. Rokita E, Rok T, Taton G. Application of thermography for the assessment of allergen induced skin reactions. Med Phys. 2011;38(2):765-72.

16. Rok T, Rokita E, Taton G, et al. Thermographic imaging as alternative method in allergy diagnosis. J Therm Anal Calorim. 2017;127(2):1163-70.

17. Dencheva M, Lyapina M. Study of the incidence of positive allergic reactions to local anesthetics used in dentistry for the period 2011-2017. In: 7th National Congress of allergology with international participation, Sofia, Bulgaria (2018).

Publisher's Note Springer Nature remains neutral with regard to jurisdictional claims in published maps and institutional affiliations. 